\title{
THE L1 IN EFL INSTRUCTION, A BENEFICIAL RESOURCE OR A 'LIFE VEST'? PERSPECTIVES OF A BILINGUAL NEST AND A NON-NEST
}

\author{
Irene Millán Maciá, Escuela Oficial de Idiomas, Torrevieja (Alicante) \\ Email: millanmacia@gmail.com
}

\begin{abstract}
This study examines the differences in teaching behaviour, particularly regarding the amount and reasons behind the use of the L1 by a NEST and a non-NEST. The results did not entirely match those of similar studies, showing that the NEST made a more extensive use the L1 than the non-NEST. Students' advanced level and a lack of awareness of the relevance of the $\mathrm{L} 1$ influence teachers' attitudes in this regard. This study highlights the need of raising awareness about the importance of the L1 as a cognitive and social tool in EFL instruction, also when teaching advanced learners.

Keywords: English as a Foreign Language, L1, multilingualism, code-switching, NESTs, non-NESTs, teachers' perspectives.

Resumen: Este artículo examina las diferencias en el uso de la lengua materna por parte de dos docentes de inglés como lengua extranjera, una nativa y un no nativo. Los resultados no coinciden totalmente con los de otros estudios similares, ya que indican que la nativa recurre a este recurso mucho más que el no nativo. El nivel avanzado de los alumnos y la falta de concienciación sobre la importancia de la lengua materna influyen en la práctica de ambos participantes. Los resultados ponen de relieve la necesidad de concienciar a los docentes sobre los beneficios de la lengua materna a nivel social y cognitivo, también con alumnos adultos.

Palabras clave: Inglés como lengua extranjera, lengua materna, multilingüismo, cambio de código, profesores nativos de inglés, profesores no nativos de inglés, perspectivas de los profesores.
\end{abstract}

\section{INTRODUCTION}

Research comparing NESTs (native English Speaking Teachers) and non-NESTs (nonNative English Speaking Teachers) teaching practices has traditionally pointed out their use of their students' mother tongue (L1) as one of the main differences between them (Reves \& Medgyes, 1994; Árva \& Medgyes, 2000; Lasagabaster \& Sierra, 2005). This finding, however, comes as no surprise since the NESTs participants had little or no knowledge of their students' L1.

The widespread assumption that students' L1 should be minimized (Auerbach, 1993), together with NESTs' historical privileged status, and the market's preference for them 
(Madrid \& Cañado, 2004), account for the fact that research comparing NESTs and nonNESTs has mainly looked into the perspectives of monolingual instructors.

Nevertheless, with the gradual shift into a multilingual approach of language teaching, the relevance of the students' L1 is becoming more visible (Brooks-Lewis, 2009); with experts, more often than not, arguing for the incorporation of students' $\mathrm{L} 1$ in the classroom (Cook, 2001 and 2005; Creese \& Blackledge, 2010a; Cummins, 2009; García, 2009a; Macaro, 2005). In this line, authors like Barratt \& Kontra (2000) and Lasagabaster \& Sierra (2005) urge NESTs to become familiar with their students' L1 and culture, in order to compare languages, predict students' doubts and mistakes, and also build multicultural bridges.

Hence, my interest in studying the teaching perspectives of a bilingual NEST and a non-NEST teaching English to adults at an Official School of Languages (Escuela Oficial de Idiomas or EOI) in Spain: in order to see how these language instructors make use of their students' L1, a resource that both have at their disposal; and whether and to what extent their status as NEST and non-NEST, as well as other factors, such as students' advance level of English (Cummings, 2009) or teachers' lack of knowledge of the last teaching trends (Rivers \& McMillan, 2011), influence their decisions in this regard.

In order to throw light on the issues mentioned, the present study addresses the following research questions:

- $\quad$ To what extent is Spanish used as the L1 in the EOI?

- For what purposes is it used?

- What are the differences in its use between native and non-native teachers?

- What are the perceptions of teachers towards using Spanish in the EFL (English as a foreign language) classroom?

\section{LITERATURE REVIEW}

Over the last century the use of the mother tongue in EFL instruction has been seen as a controversial issue (Levine, 2003). Especially since the rise of the Communicative Language Teaching Method, which contributed to the assumption of a series of practices underlying the monolingual approach, as it advocates for a maximum exposure to the target language, ignoring the existence of the L1 (Miles, 2004).

\subsection{Multilingualism, a reaction to the monolingual approach}

Although the influence of English-only classroom is still very strong nowadays, a growing number of studies have challenged it from different theoretical frameworks, such as multilingualism. Research into multilingual discourse argues that language users resource to their languages to make meaning (Creese \& Blackledge, 2010b; García, 2009a; Macaro, 2005).

This shift towards a multilingual approach in language teaching comes as no surprise in the current context of globalisation, with the continuous interchange of ideas, culture and people, individuals' communication practices have become more diverse than ever (Blommaert \& Rampton, 2011). This diversity manifests in people's negotiations over linguistic resources, a phenomenon that has been explained by several authors, who have coined terms such as 
"flexible bilingualism" (Creese \& Blackledge, 2010a) or "translanguaging” (García, 2009b) in order to describe "the multiple discursive practices that plurilinguals engage in as they make meaning with one another" (Taylor \& Snoddon, 2013: 440).

Multilingual communicative practices are having an impact on TESOL (Teaching English to Speakers of Other Languages) settings, where they gradually reflect on educational practices by recognising the crucial role that learners' linguistic repertoires play in learning English (Taylor \& Snoddon, 2013).

Based on data from her research in the context of bilingual schools in the USA, García (2009b) advocates for the recognition of the important role of students' home languages. This includes not only bilingual education, but also the teaching of English to speakers of other languages.

\subsection{Multilingualism in the classroom: Using the L1}

The question that arises now among the foreign language teaching and research community is how to translate into the classroom the communicative strategies that multilinguals display naturally (Canagarajah, 2011). The body of research that studies the uses of the L1 in the foreign language classroom argues for a systematic way of supporting L2 (foreign language) learning by a judicious use of the L1 (Cook, 2001; Turnbull, 2001; Cummins 2009).

Cummins (2009) presents the main reasons why teachers should not ignore the L1: Firstly, learners' pre-existing knowledge, the base of any future learning, is encoded in their L1. Secondly, translation constitutes an easy way to enhance linguistic awareness. Besides, for languages that share many cognates, a focus on these can enhance students' vocabulary in the L2.

Cook (2001) suggests specific instances in which teachers can use this resource: For conveying the meaning of words or sentences, as it may be an efficient way to help the learners to identify similarities and differences between languages. Also to explain grammar, even at advanced levels, since it makes the teaching more efficient. Some teachers also resort to the L1 when giving instructions, especially with beginners, again for the sake of effective learning. When it comes to gaining contact with individual students, for example to praise them or to make personal remarks, it may be more natural to do in the L1 as well.

Research conducted by others based on teachers' self-reports, observations and students' questionnaires not only confirmed the claims made by Cook, but it also identified further instances where the L1 was used: When building personal relationships with the learners (Macaro, 2000a; cited in Macaro, 2005), for administrative purposes, to show empathy with the learner, for the teacher to practice the students' L1 with their tutoring, to remedy students' lack of comprehension (Polio \& Duff, 1994), and to provide the necessary scaffolding for learning (Littlewood \& Yu, 2011).

\subsection{Teachers' perspectives towards the $\mathrm{L} 1$}

In spite of the gradual acceptance of the L1 as a beneficial asset in foreign language instruction, articulating specific instances where this resource maximises the L2 learning is a difficult task due to the large number of influencing factors that shape teachers' use 
of the L1 (Moore, 2013). Therefore, as important as the instances where teachers use the L1 are as well the factors behind teachers' use of the L1 (De La Campa \& Nassaji, 2009).

In a study in 1990 Duff and Polio identified two groups of factors that determined teachers' language choice: external and internal. The former included those variables that are relatively stable: students' proficiency in the L2, the level of similarity between the L1 and the L2, teachers' educational background and the departmental policy regarding the use of the mother tongue. The second set of variables was "related to features of language use or activities at a given time of the instruction" (Duff \& Polio, 1990: 155).

Other important factors that can account for the teachers' use of their students' L1 include their status as native or non-native speakers (Arva \& Medgyes, 2000), the motivation of the EFL learners, the context and the cultural background (Kuhi \& Abdolvash, 2013). A powerful element that influences pedagogical practices regarding the use of the L1 is teachers' beliefs and perceptions (Levine, 2003). In turn, such beliefs are shaped by instructors' learning and teaching experiences, teacher training, and exposure to colleagues or supervisors' opinions (Rivers \& McMillan, 2011). Teachers' familiarity with the literature on second language learning can also influence their use of the L1, although not as much as what Levine (2003: 343) refers to as "classroom experience and intuitions about what feels right", two factors that seem to be decisive for teachers when resorting to the L1.

\subsection{NESTs, non-NESTs and the L1}

As mentioned above, a series of studies have pointed out as decisive teachers' status as NESTs or non-NESTs when resourcing to the L1 (Reves \& Medgyes 1994; Árva \& Medgyes, 2000; Lasagabaster \& Sierra, 2005).

In a seminal article published in 1994, Reves and Medgyes compared NESTs and nonNESTs, revealing the differences between NESTs and non-NESTs language competence would account for most of the differences between their teaching practices. However, since language competence is not the only variable of teaching skills, NESTS are not necessarily better language instructors than non-NESTs (Reves \& Medgyes, 1994). The author concludes that what might be seen as a weakness - their language competence - is actually a facilitator of the teaching process.

This and other aspects of NESTs' and non-NESTs' teaching behaviour became evident in another study conducted in 2000 by Árva and Medgyes in the Hungarian context. The data, collected among 10 teachers at secondary schools in Budapest, was obtained from interviews and recorded lessons. The observations showed NESTs' linguistic advantage over non-NESTs, but also an interest in the Hungarian culture that NESTs deployed to build cross-cultural bridges and boost communication with their students.

On the other hand, although virtually all the non-NESTs in the sample showed a very good command of English and used it almost exclusively during their lessons, they did not demand their students to do the same. Non-NESTs' lessons, unlike those of NESTs, did not include much content of the target culture, and there was either no attempt to compare it with the Hungarian one.

From the interviews, NESTs' lack of Hungarian arose as a handicap, especially when teaching beginners, communicating with students or interpreting some of their mistakes. 
NESTs and non-NESTs were of the opinion that natives' lack of Hungarian was a defect in the professional expertise. Therefore, NESTs taught conversation, leaving everything else for non-NESTs.

The results of this study, as far as the use of the L1 is concerned, are not surprising as the NESTs participants had no or very little knowledge of their students' mother tongue. However, would their use of this resource had been different had the NESTs been more proficient in Hungarian?

In another study conducted by Lasagabaster and Sierra (2005) on students' opinions about NESTs and non-NESTs in the Basque context, students acknowledged the disadvantages of monolingual NESTs. A high percentage of the participants gave special importance to translation and comparison between languages as pedagogical tools. Not surprisingly, one of the conclusions of this study was the importance for NESTs to learn the local language and become familiar with the local culture in order to become better teaching professionals.

\section{METHODOLOGY}

\subsection{The context}

The study was carried out in two groups of the same course of EFL in an EOI at the Alicante province. The course was aimed at obtaining the accreditation of the $\mathrm{C} 1$ level of the Common European Framework of Reference for Languages.

The classes were held twice a week for 1.5 hours, and the courses from October to May. Each class contained 14 and 13 students respectively ranging in age from 18 to 60 . One class had 7 female and 7 male students, while the other had 7 female and 6 male students; all of them had grown up in Spain.

\subsection{The Teachers}

The teachers were a NEST and a non-NEST. The NEST, Sharon (pseudonym), is a 50-year-old teacher who has taught English in Spain for about 24 years, 10 of which at the EOI. Her academic background was in English Philology, a degree earned from a Spanish university. The other teacher is Federico (pseudonym), a 42-year-old-teacher, with 10 years of experience teaching English at state secondary schools in Spain, and 7 at the EOI. He had a degree in English Philology earned at a Spanish University. Both teachers had completed the official course that qualifies them as teachers in Spain.

\subsection{Data-gathering tools and procedures}

To answer the research questions, data from two sources was collected: audio recordings of the English classes (two observations, each of approximately 90 minutes with each participant) and interviews with the teachers, which included recall sessions to help them reflect on their practice. The audio recordings were used to capture the 
moments when the teachers used the L1. However, since it was possible that they did not use Spanish at all, the researcher looked as well for instances where the L1 could have been helpful.

Two semi-structured interviews were conducted with each teacher individually. The first aimed to explore their general beliefs and attitudes towards the L1, and to reflect on some excerpts from the observations. A follow-up interview was conducted later on, so that the participants had time to reflect on the topic of the use of the L1 in their classes and to further comment on some more observation excerpts.

The interviews were conducted in Spanish with Federico, as he and the author are native speakers of Spanish, and in English with Sharon. The interviews were transcribed, translated back to English in the case of Federico, and then coded for analysis.

\subsection{Coding}

After listening to the recorded lessons, relevant excerpts were identified and transcribed. Sharon's higher theme was "instances where the L1 is used", whereas Federico's was "instances where the L1 would have been useful", as he never switched into Spanish during the lessons recorded.

From the interpretation of the data, a series of codes emerged without any predetermination (Saldaña, 2009), which, in the case of Sharon were: "cultural references to students' context", "comparison between the Spanish and the British cultures", "comparing languages" (with the subcategories of "similarities" and "differences"), "providing equivalents" and "teacher as a language learner.

For Federico the codes that emerged from the interpretation of his lesson excerpts were the following: "comparing languages" (with the subcategories of "similarities" and "differences"), "providing equivalents", "giving procedural instructions", and "comparing cultures".

The themes chosen to gain insight into the experiences and beliefs that may have shaped the participants' use of the L1 emerged from the literature on this topic and are classified in: past learning experiences, teacher training, past teaching experiences, exposure to colleagues' or supervisors' opinions (Rivers \& McMillan, 2011), teachers' status as NEST or non-NEST (Arva \& Medgyes, 2000), motivation of the EFL learners, context (Kuhi \& Abdolvash, 2013), students' proficiency in the L2, level of similarity between the L1 and the L2, departmental policy regarding the use of L1, type of the activity or skill taught (Duff \& Polio, 1990).

\section{DATA ANALYSIS}

\subsection{Analysis of the recorded lessons}

In line with other studies examined in the literature review (Reves \& Medgyes, 1994; Árva \& Medgyes, 2000; Lasagabaster \& Sierra, 2005), the NEST and the non-NEST participants differ significantly in their use of Spanish during EFL instruction. What is 
striking is that the native participant resources quite often to her students' L1, whereas the non-NEST used exclusively English in the lessons observed. In the following section, Sharon's use of Spanish is analysed. In addition to this, instances where Spanish could have been useful during Federico's lesson are examined.

\subsection{Sharon's use of the L1}

The data from the observations showed that Sharon code-switches quite often. Her uses of Spanish are limited to words or short sentences. The L1 was particularly noted when the teacher was comparing languages and providing equivalents. Additionally, the L1 was used in the form of references to the Spanish context, and also as a way to compare the Spanish and the British cultures. Interestingly, the L1 was also used by the teacher in order to present herself as a language learner.

The excerpt selected demonstrates features representative of Sharon's use of the L1 (marked in bold). It belongs to Sharon's second observation. The teacher began the class by referring to the homework, giving feedback on the student's' most common mistakes:

\section{$(\ldots)$}

Sharon: Flight, another preposition. The preposition with flight, en un. vuelo? How was the...?

Student 1: On a flight.

Sharon: On a flight, ok? Some of you wrote "in a flight" because in.

Spanish is en un vuelo, ok? o en el vuelo but in English the preposition is. 'on', ok?

The pedagogical purposes of this use of the students' L1 came up during the interviews. Sharon resources to Spanish to draw her students' attention to mistakes that have their origin in the differences between English and Spanish.

The second most common purpose for Sharon to use Spanish in the classroom is to provide her students with equivalents. For example, when the expression "to make head or tails" came up, Sharon compared it with the Spanish equivalent, in her own words "to see if they can make the connection with the Spanish and the English expression.".

A further purpose of this use of the L1 emerged during the interviews, and concerns Sharon's own interest in the Spanish language. Although after explaining it, the meaning of the expression "you can say that again" is clear to the students, Sharon asks for the Spanish equivalent to satisfy her own curiosity. Seeking her students' tutoring (Polio \& Duff, 1994) brings about a good atmosphere in the classroom, and contributes to eliciting synonyms in English of the expression in question, enriching the students' vocabulary.

A cross-cultural relationship (Árva \& Medgyes, 2000) is clearly seen in Sharon's comparisons between the Spanish and the British culture. These constitute a rich source of cultural information which, in Sharon's opinion cannot be separated from a language. Besides, the acknowledgement of cultural differences within the classroom contributes boosts students' speaking practice and contributes to their learning (Benke \& Medgyes, 2005). As it can be seen in the following excerpt Sharon repeats the word "hypocritical" in order to correct the student's pronunciation: 
Sharon: Who do you think speaks their mind more, the Spanish or the British?

Students: The Spanish.

Sharon: Can you give any examples of when you speak your mind? There are some things that offend me, when you speak your mind that for British people is inconceivable. For example, when you have lunch and somebody has spent a long time cooking the lunch you say: oh there is not quite enough salt in the paella today. A British person would not say that, a British person would say "it's delicious, it's delicious, absolutely delicious".

Student 3: But that's a little bit, from my point of view, it's a little bit hypocritical.

Sharon: Hypocritical. I'm not saying if it's right or wrong.

It is commonly accepted that only non-NESTs serve as good model of language learner (Medgyes, 2001). This is due to the fact that studies comparing NESTs and non-NESTs have traditionally had monolingual NESTs participants. This is precisely one of the handicaps for NESTs that students usually mention (Barratt \& Kontra, 2000; Bolitho \& Medgyes, 2000; Lasagabaster \& Sierra, 2005). However, NESTs, like Sharon, who share their students' L1, can serve as good models of language learners (Lasagabaster \& Sierra, 2005). By recognising her language handicaps in Spanish, Sharon shows empathy with her students, and it also encourages them to speak:

Sharon: And what about your language? What problems do you think I had when I started learning Spanish? And even now as well.

Student 1: The verb forms are the most complicated thing in Spanish

Sharon: Well all your verbs are irregular, basically. Like the verb caber, yo cabo, tu quepas, impossible!

\subsection{Federico's use of the L1}

Some of the hypotheses suggested by other studies (Árva \& Medgyes, 2000; Lasagabaster \& Sierra, 2005; Reves \& Medgyes, 1994) regarding the differences between NESTs and non-NESTs are validated in this study. However, regarding the use of the L1 in EFL instruction, there is an interesting twist: the non-NEST did not once use Spanish during the lessons observed. This avoidance of the L1 had detrimental effects on his students' learning, especially in terms of efficiency when explaining vocabulary, helping students identify similarities and differences between languages (Cook, 2001) and remedying lack of comprehension (Duff \& Polio, 1990). Besides, there were very few cultural references, even though the speaking activities provided a very good opportunity to discuss this topic. This could have encouraged students to participate in the speaking activities, as they were a bit reluctant to do so.

Identifying differences between languages is one of the instances where it is recommended to use the L1 (Cook, 2001). It is currently accepted that, in second language development, there is an interaction between the L1, cognitive processes and the input in the L2 (Lightbown \& Spada, 2013). A cross-linguistic influence that can be positive or negative, but that either way it is valuable to explicitly point out, to raise awareness about the similarities and differences between languages, and to avoid the fossilisation of wrong knowledge (Benson, 2002). Such use of the L1 would have been helpful in Federico's 
lessons, as the cross-linguistic influence from his students' L1 accounted for many of their mistakes in English. However, in these situations, Federico's tendency is to provide grammar-based feedback, which may be too sophisticated for those who do not have a background in Linguistics.

The following excerpt shows an instance where Federico's feedback would have been more effective if it had been complemented with a comparison with the L1. It belongs to Federico's second observation. The teacher reads out an open-cloze exercise and the students, in turns, complete the task:

Federico: "But how do animals travel huge distances to precise.

destinations...?"

Students: Without.

Federico: "Without a map or a GPS?" number 12?

Student 1: No.

Federico: "No single answer to this is available". No, yes?

Student 2: It can be any?

Federico: No, no single. No single answer to this. It's a positive verb. Is available.

From the observations, it was clear that Federico did not have his message across. Whereas students may not know what a "positive verb" is, they would have easily understood that, although in Spanish "any" is used to reinforce negative sentences; this is not the case in English.

Even at advanced levels of foreign language instruction, the link between the L1 and the L2 should not be ignored, as it can facilitate the acquisition of sophisticated vocabulary (Hulstijn et al., 1996). Precisely, having a wide range of vocabulary in both, formal and informal registers, is especially important at this level. In this sense, when reviewing vocabulary of different registers at the beginning of the first session, providing the Spanish equivalent would have enhanced students' linguistic awareness (Cummins, 2009). By doing so, Federico would have helped the students understand the different registers these expressions belong to. Besides, one of the students wrongly suggests "to stick to somebody" as an equivalent for "to tag along somebody". Although Federico tries to make clear that they are not synonyms, he does not emphasise this enough. If he had used a Spanish equivalent, the students would have understood the meaning of the expressions, avoiding possible error fossilisation.

At another moment, there is a communication breakdown between Federico and one of the students. The learner is doing an exercise where some sentences, which are too informal, need to be replaced by a more suitable option. From the observation it is not clear whether the student is lost because she does not understand what she has to do, or because she does not know which sentence she needs to replace. But either way the L1 could have been beneficial to remedy the lack of comprehension (Duff \& Polio, 1990), to give procedural instructions (Macaro, 2005), or to provide an equivalent for the informal and informal options in the exercise. 


\subsection{Analysis of the interviews}

The participants' respective statuses of NEST and non-NEST seem to have some impact on their use of Spanish: Federico is the opinion that if he was native, students would "forgive" him for using Spanish, as they would think that he does it for their own benefit. Sharon, on the other hand, is aware of the fact that she can "get away" with things like not remembering a particular word in English, because she is a native.

However, a decisive factor that shapes both teachers' use of Spanish is the students' proficiency level. The participants agree that the use of the L1 should decrease as the proficiency level increases, being necessary at lower levels, but not at the $\mathrm{C}$ levels, where Federico sees it as a "life vest".

Another powerful factor is, as Levine (2003: 343) points out, "intuitions about what feels right". In this regard, different elements come into play to shape Sharon's teaching practices: On one hand her awareness of the usefulness of the L1 for translating and providing equivalents. An awareness that has been raised by certain knowledge of the literature on the topic. Additionally, the fact that she does not feel constrained by the school policy, or what her students or colleagues may think, allows her to use Spanish to a greater extent than Federico, who is constrained by some sort of 'hidden policy':

Federico: (...)it's at the department level(...)It is assumed that it's not very professional to use Spanish at higher levels(...)Besides, they stigmatise you as soon as you say four things in Spanish.

Although it is unclear if the other teachers at the English department follow such hidden policy, there is an indication that there may be a common belief among them that the use of the L1 should be minimised: During one of the interviews with Sharon it came up that teachers have agreed to speak in English in front of the students, although, normally, their language of communication among them is Spanish.

Even though Sharon code-switches with certain regularity into Spanish, there is not a total correspondence "between teachers' espoused beliefs and classroom behaviour" (Clark \& Peterson, 1986, cited in Árva \& Medgyes, 2000: 358). From her discourse emerges a certain reluctance to acknowledge the extent to which she uses Spanish and its relevance, especially at the higher levels. Previous teaching experiences and the exposition to other colleagues' perspectives (Rivers \& McMillan, 2011) led Sharon to make a "conscious decision" of not speaking Spanish, a pattern that is quite powerful in her discourse.

Sharon: (...) with the other native speaker because we talked a lot about what we do in class. She says "I only speak to them in Spanish at basic level" and because of her I was making an effort to speak in English even if they are very basic.

In spite of Federico's firm conviction that at the higher levels, Spanish is only to be used as the last resource, in the course of the follow-up interview there are signs of a shift in the non-NEST attitude towards the L1:

Probably in those cases, this may help me was well, because maybe, next year I know that in certain situations is not bad to use Spanish. 
This suggests that Federico has never reflected on the pedagogical uses of the mother tongue, and how a judicious use can make a considerable difference, as the analysis of the observation excerpts suggests.

In fact, the latest trends in EFL teaching suggest that the acknowledgement of the students' mother tongue should go beyond the classroom, incorporating it into English language testing (Llurda, 2004), a potential use that Sharon does not consider relevant, while Federico has never reflected on it.

\section{CONCLUSIONS}

The findings of this study are in line with other authors' claims that the L1 is a valuable resource in foreign language teaching (Cook, 2001 and 2005; Cummins, 2009; Macaro, 2005), also at higher levels (Cummins, 2009), where it can help teachers to clarify meaning of sophisticated vocabulary, explain differences between registers, compare languages, and avoid communication breakdowns. Additionally, an acknowledgement of students' cultural context constitutes a beneficial pedagogical tool, as it helps to build cross-cultural bridges that boost speaking in the L2.

For these reasons it is important that NESTs learn their students' L1, and that nonNESTs make use of this resource. Unfortunately this is not always the case and, as the findings of this project reveal, NESTs and non-NESTs see with reservations the use of the L1, especially at high proficiency levels.

Attitudes towards the L1 depend on different factors. In this case, teachers' status as NESTs or non-NESTs shapes, to a certain extent, their decisions when using the L1. Interestingly, and unlike what other studies, when teaching non-NESTs may use less amounts of L1 than their bilingual NESTs counterparts, for fear of seeming unprofessional in the eyes of their students and colleagues.

Nevertheless, other factors such as the students' advanced level, led teacher-participants in this study to avoid the L1, in the case of the non-NEST, or to discrepancies between beliefs and the actual practice, in the case of the NEST.

Especially remarkable was the change of attitude of the non-NEST teacher, after being exposed to some of the communication problems and breakdowns that he had during the lesson observed, which the L1 could have solved.

Two conclusions can be therefore drawn from this study: On one hand, the need to use classroom observation to help teachers to reflect on their practice (Llurda, 2004). On the other hand, the urgent need of exposing teachers to the debates around the topic of the L1, by incorporating it to continuous professional development programmes, but also as part of language teacher training curricula. These programmes should emphasise the relevance of the L1 as a useful cognitive and social tool (Moore, 2013), also at high proficiency levels of a foreign language. Additionally, the incorporation of the L1 should go beyond codeswitching, by acknowledging students' culture, and incorporating the L1 in EFL testing (Lasagabaster \& Sierra, 2005).

The generalizability of findings in this study is limited by the context, the background of the teachers, and the size of the sample. Besides, due to time restrictions, the research focused only on two lessons with each participant. 
Therefore, it would be interesting to explore the perspectives of a bigger sample of bilingual NESTs and non-NESTs during a longer period of time, and also those of students, since teachers' perceptions do not suffice to build a framework of how to integrate the L1 in the EFL classroom. Moreover, with a view of improving teacher training, it would be of value to assess the effects of exposing foreign language teachers to current debates around the use of the L1.

\section{REFERENCES}

Árva, V., \& Medgyes, P. 2000. "Native and non-native teachers in the classroom.” System: 28(3), 355-372.

Auerbach, E. R. 1993. "Reexamining English only in the ESL classroom.” Tesol Quarterly: 27(1), 9-32.

Barratt, L., \& Kontra, E. H. 2000. "Native-English-speaking teachers in cultures other than their own." TESOL journal: 9(3), 19-23.

Benson, C. 2002. “Transfer/Cross-linguistic influence.” ELT journal: 56(1), 68-70.

Benke, E., \& Medgyes, P. 2005. "Differences in teaching behaviour between native and non-native speaker teachers: As seen by the learners." In Llurda, E. (Ed.). Non-native language teachers: Perceptions, challenges and contributions to the profession. New York, NY: Springer. 195-215.

Blommaert, J., \& Rampton, B. 2011. “Language and superdiversity.” Diversities: 13 (2). 1-22.

Bolitho, R., \& Medgyes, P. 2000. “Talking shop: from aid to partnership.” ELT Journal: 54(4), 379-386.

Brooks-Lewis, K. A. 2009. "Adult learners' perceptions of the incorporation of their L1 in foreign language teaching and learning.” Applied Linguistics: 30(2), 216-235.

CAnagarajah, S. 2011. "Codemeshing in academic writing: Identifying teachable strategies of translanguaging.” The Modern Language Journal: 95(3), 401-417.

Cook, V. 2001. "Using the first language in the classroom." Canadian Modern Language Review: 57(3), 402-423.

----. 2005. "Basing teaching on the L2 user." Non-native language teacher's, 47-61. Springer US.

Creese, A., \& Blackledge, A. 2010a. "Translanguaging in the bilingual classroom: A pedagogy for learning and teaching?" The Modern Language Journal: 94(1), 103-115.

---- 2010b. "Towards a sociolinguistics of superdiversity." Zeitschrift für Erziehungswissenschaft: 13(4), 549-572.

Cummins, J. (2009). "Multilingualism in the English-language classroom: Pedagogical considerations." TESOL quarterly: 43(2), 317-321.

De La CAmpa, J. C., \& NAssaj, H. 2009. “The amount, purpose, and reasons for using L1 in L2 classrooms." Foreign Language Annals: 42(4), 742-759. 
Duff, P. A., \& Polio, C. G. 1990. "How much foreign language is there in the foreign language classroom?" The Modern Language Journal: 74(2), 154-166.

----. 1994. “Teachers' language use in university foreign language classrooms: A qualitative analysis of English and target language alternation." The Modern Language Journal: 78(3), 313-326.

Dujmović, M. 2007. "The use of Croatian in the EFL classroom.” Metodički obzori: 2(3), 91-101.

Edstrom, A. 2006. "L1 use in the L2 classroom: One teacher's self-evaluation." Canadian Modern Language Review: 63(2), 275-292.

García, O. 2009a. Bilingual education in the 21st century: A global perspective. John Wiley \& Sons.

----.2009b. "Emergent Bilinguals and TESOL: What's in a Name?" Tesol Quarterly: 43(2), 322-326.

Hulstijn, J. H., Hollander, M., \& Greidanus, T. 1996. “Incidental vocabulary learning by advanced foreign language students: The influence of marginal glosses, dictionary use, and reoccurrence of unknown words." The modern language journal: 80(3), 327-339.

Kuni, D., \& AbDolvash, M. 2013. “Azerbaijani Turkic speaking English language teachers' attitudes towards the use of their students' mother tongue in English classes." International Journal of Research Studies in Language Learning: 3(3).

Lasagabaster, D., \& Sierra, J. M. 2005. "What do students think about the pros and cons of having a native speaker teacher?” In Non-native language teachers: 217-241. Springer US.

LEVINE, G. S. 2003. "Student and instructor beliefs and attitudes about target language use, first language use, and anxiety: Report of a questionnaire study." The Modern Language Journal: 87(3), 343-364.

Lightbown, P. M., Spada, N., Ranta, L., \& Rand, J. 2013. How languages are learned (Vol. 998). Oxford: Oxford University Press.

Littlewood, W., \& Yu, B. 2011. "First language and target language in the foreign language classroom." Language Teaching: 44(01), 64-77.

LLURDA, E. 2004. "Non-native-speaker teachers and English as an International Language." International Journal of Applied Linguistics: 14(3), 314-323.

MacAro, E. 2005. "Codeswitching in the L2 classroom: A communication and learning strategy." Non-native language teachers: 63-84. Springer US.

MADRID, D. \& CAÑADO, M.L. 2004. “Teacher and student preferences of native and nonnative foreign language teachers." Porta Linguarum: 125-138.

Medgyes, P. 2001. "When the teacher is a non-native speaker." Teaching English as a second or foreign language: 3, 429-442.

MiLes, R. 2004. Evaluating the use of L1 in the English language classroom (Doctoral dissertation, University of Birmingham). 
Moore, P. J. 2013. "An Emergent Perspective on the Use of the First Language in the Englishas-a-Foreign-Language Classroom.” The Modern Language Journal: 97(1), 239-253.

Reves, T., \& Medgyes, P. 1994. "The non-native English speaking EFL/ESL teacher's selfimage: An international survey." System: 22(3), 353-367.

Rivers, D. J. \& McMillan, B. A. 2011. “The practice of policy: Teacher attitudes toward 'English only"'. System: 39(2), 251-263.

SALDAÑA, J. 2009. The coding manual for qualitative researchers. London: Sage.

TAYLOR, S. K., \& SNODdON, K. 2013. "Plurilingualism in TESOL: Promising controversies." TESOL Quarterly: 47(3), 439-445.

Turnbull, M. 2001. "There is a role for the L1 in second and foreign language teaching, but..." Canadian Modern Language Review: 57(4), 531-540 